\title{
PERIGOSIDADE A CHEIAS NO RIO UÍMA (SANTA MARIA DA FEIRA, PORTUGAL): ENSAIO METODOLÓGICO DE SUPORTE À IMPLEMENTAÇÃO DA DIRETIVA 2007/60/CE
}

\section{FLOOD DANGER IN THE UÍMA RIVER (SANTA MARIA DA FEIRA, PORTUGAL): METHODOLOGICAL ESSAY TO SUPPORT THE IMPLEMENTATION OF THE DIRECTIVE 2007/60/CE}

\author{
Inês Marafuz \\ Faculdade de Letras, Universidade do Porto \\ Via Panorâmica, s/n, Porto, Caixa Postal: 4150-564, Portugal \\ E-mail:ines.mfuz@gmail.com \\ Rui Adelino \\ Divisão de Planeamento, Câmara Municipal de Santa Maria da Feira \\ Praça da República, 135, Santa Maria da Feira, Caixa Postal: 4524-909, Portugal \\ E-mail: rui.adelino@urbanfeira.net
}

António Alberto Teixeira Gomes

Faculdade de Letras, Universidade do Porto

Via Panorâmica, s/n, Porto, Caixa Postal: 4150-564, Portugal

E-mail:albgomes@gmail.com

\section{Informações sobre o Artigo \\ Data de Recebimento: \\ 30/04/2014 \\ Data de Aprovação: \\ $21 / 07 / 2014$}

Palavras-chave:

Perigosidade a cheias;

Elementos expostos; Hec-Ras;

Diretiva 2007/60/CE

\section{Keywords:}

Flood hazard; Exposed elements; Hec-Ras; Directive 2007/60/CE

\section{Resumo:}

O aumento dos episódios de cheias e consequentes perdas humanas e prejuízos materiais tem conduzido a uma crescente preocupação por parte dos governos europeus e das autoridades nacionais que lidam com estas questões. Neste contexto, a aprovação da Diretiva 2007/60/CE estabeleceu a necessidade de se efetuar uma avaliação preliminar do risco de inundação e de se produzir cartografia de apoio à minimização dos efeitos destes eventos. Neste artigo apresenta-se um ensaio metodológico para a determinação da perigosidade a cheias num setor do rio Uíma (norte de Portugal), através da aplicação de uma matriz de intensidadeprobabilidade. Esta matriz relaciona os parâmetros da velocidade e da altura da coluna de água, modelados no software Hec-Ras, com a frequência de ocorrência de cheias. No final identificaram-se, por classe de perigosidade, os elementos expostos, designadamente o edificado e as estradas. Os resultados mostram que as diferenças nos perímetros de inundação para os períodos de retorno considerados $(10,50$ e 100 anos) se destacam na área central da planície aluvial modelada. A altura da coluna de água apresenta valores mais elevados nos segmentos do rio a montante das pontes, que funcionam como barreiras à circulação da água. A velocidade da água é elevada nesses mesmos segmentos, a jusante, e no setor 
a montante, onde o vale é mais estreito. Pela conjugação destes fatores e da recorrência dos eventos, verifica-se que a perigosidade a cheias é mais elevada nos setores atravessados por pontes e no início do setor modelado. A metodologia aplicada visa ser um contributo para os municípios portugueses que terão de dispor de cartografia de áreas inundáveis similar à que se apresenta neste trabalho de forma a cumprirem o estipulado na Diretiva 2007/60/CE.

\begin{abstract}
:
The increase of flood events and consequent human losses and material damages has led to a growing concern among European governments and national authorities. In this context, the adoption of the Directive 2007/60/ CE established the need to perform a preliminary flood risk assessment and to produce applied cartography to minimize the effects of these events. This paper presents a methodological essay for the determination of flood hazard in the Uíma river sector, north of Portugal, through the application of an intensity-probability matrix. This relates the height of water column and the water velocity parameters, modelled in the Hec-Ras software, with the frequency of occurrence of floods. At the end, the exposed elements, namely the built up areas and roads, were identified for each class of danger. The results show that the large differences in the flood-prone areas for the return periods considered (10, 50 and 100 years), stands out in the middle of the modelled alluvial plain. The height of water column presents higher values in the segments of the river upstream of the bridges, which act as barriers to the water circulation. The water velocity is high in those segments and in the upstream sector, where the valley is constricted. By the combination of these factors and the recurrence of the events, it appears that the flood danger is higher in the sectors crossed by bridges and at the beginning of the modelled sector. The applied methodology aims to be a contribution to the Portuguese municipalities that have to achieve similar results which is presented in this work, in order to fulfil the requirements stipulated in the Directive.
\end{abstract}

\section{Introdução}

As últimas décadas têm sido marcadas pelo aumento dos episódios de cheias um pouco por toda a Europa (Alphen et al., 2009; Barredo, 2007). Este cenário explica-se em grande parte pela expansão dos espaços urbanos ao longo de planícies de inundação, as quais enfrentam assim uma mudança na sua dinâmica natural (Barredo, 2007; Du et al., 2012; Hollis, 1976).

A intensificação destes eventos tem levado a significativas perdas humanas e a avultados prejuízos em infraestruturas, bens e serviços, motivando uma crescente preocupação por parte dos governos europeus e das diversas autoridades nacionais (Em-Dat; Jonkman, 2005; Douben, 2006, Zêzere et al., 2014). Neste contexto, foi aprovada a Diretiva 2007/60/CE do Parlamento Europeu e do Conselho da União Europeia, de $23 \mathrm{Ou}-$ tubro de 2007, que prevê a redução das consequências das cheias, por meio do estabelecimento de um quadro normativo para a avaliação e gestão destes eventos.

A Diretiva determina como requisitos necessários ao seu cumprimento: a avaliação preliminar dos riscos de inundações; a elaboração de cartas de zonas inun-

\footnotetext{
${ }^{1} \mathrm{http}: / /$ ec.europa.eu/environment/water/flood_risk/timetable.htm
}

${ }^{2}$ http://riskam.ul.pt/disaster/ dáveis que contemplem cenários de eventos extremos, eventos de média probabilidade com períodos de retorno iguais ou superiores a cem anos e eventos de elevada probabilidade de ocorrência com periodicidade inferior a cem anos, para áreas densamente povoadas (Decreto -Lei n. ${ }^{\circ}$ 115/2010, de 22 de Outubro); e a elaboração de cartas de risco de cheias. Nestas, deverão ser indicadas as possíveis consequências das cheias, nomeadamente o número de pessoas potencialmente afetadas, os tipos de atividade económica e as áreas protegidas afetadas, entre outros. Com base nos resultados das cartas mencionadas deverão ser elaborados, até 2015, os planos de gestão de risco de cheia.

Em Portugal têm sido promovidos esforços no sentido de se fazerem cumprir os requisitos da Diretiva 2007/60/CE dentro dos prazos estabelecidos, tendo já sido concluídas três etapas ${ }^{1}$, nomeadamente a transposição da Diretiva para a legislação portuguesa (Decreto-Lei n. ${ }^{\circ}$ 115/2010, de 22 de Outubro), a designação das autoridades competentes e das unidades de gestão e a avaliação preliminar dos riscos de inundação. Recentemente, o projeto DISASTER ${ }^{2}$ apresenta um importante contributo a nível nacional, compilando 
numa base de dados SIG as ocorrências de origem hidro-geomorfológica (cheias e movimentos de vertente) que se registaram entre 1865 e 2010 (Santos et al. 2014; Pereira et al., 2012) e que tiveram consequências diretas sobre a população, i.e., eventos que provocaram mortos, feridos, e/ou desaparecidos, deslocados e/ou desalojados (Bateira et al., 2013). De acordo com os resultados desse projeto, verificou-se que a maior parte dos eventos $(85,2 \%)$ corresponderam a casos de cheias (Zêzere et al., 2014).

Segundo o estudo de Moel et al. (2009), os mapas de inundações produzidos na Europa são, sobretudo, referentes à extensão das cheias ( 23 dos 29 países analisados, nos quais se inclui Portugal). No caso português, a delimitação dos perímetros de inundação ou extensão da inundação (Decreto-Lei n. ${ }^{\circ}$ 166/2008, Julião et al., 2009), é baseada nos níveis de marcas de cheia, notícias de jornais e registos dos agentes de proteção civil e, com menos frequência, na modelação de pequenas áreas para as quais existam dados detalhados de altimetria.

Assim, neste trabalho, apresenta-se um ensaio metodológico para a determinação da perigosidade à ocorrência de cheias, num setor da bacia hidrográfica do rio Uíma, localizado no concelho de Santa Maria da Feira, Norte de Portugal (Figura 1A). O processo implica a conjugação de alguns resultados preliminares modelados no software Hec-Ras, designadamente os perímetros de inundação, a altura da coluna de água e a velocidade da mesma. Por outro lado, visa também a identificação dos elementos expostos tendo em conta a classe de perigosidade em que se localizam. Pelas suas características topográficas e geomorfológicas, o sector em estudo é frequentemente inundado, o que pode condicionar o normal funcionamento das atividades locais e o tráfego com os concelhos vizinhos. As cheias intensas registadas no ano de 2001, acompanhadas de perto por um dos autores e registadas por moradores e técnicos da Câmara Municipal de Santa Maria da Feira serviram de validação dos resultados obtidos com a modelação hidráulica, uma vez que este foi um ano hidrológico onde se alcançaram níveis de água muito elevados. Neste contexto, salienta-se a importância da realização do ensaio desta metodologia e da elaboração da cartografia de perigosidade a cheias, com a indicação dos elementos expostos neste setor, pelo contributo que a mesma pode dar em termos de ordenamento do território e no cumprimento das medidas propostas na Diretiva 2007/60/CE.

\section{Área de estudo}

O setor modelado localiza-se na bacia hidrográfica do rio Uíma, afluente da margem esquerda do rio Douro (Figura 1B), com um comprimento de aproximadamente 31 km e seguindo uma direção geral Sul-Norte. No seu percurso inicial, o rio Uíma corre para sudoeste (Figura 1B), sofrendo no entanto uma inflexão brusca para norte bem patente no cotovelo que desenha a noroeste de Milheirós de Poiares, facto que indica a sua captura para a bacia do Douro (Gomes, 2008). A bacia hidrográfica deste rio possui uma área de $83,2 \mathrm{~km}^{2}$, apresentando uma forma alongada (valor de 1,59 com base no Índice de Gravelius) e uma altitude média de 177,7 m (Figura 1B). A altitude na bacia varia entre os $10 \mathrm{~m}$ na foz do rio, em Crestuma, e os 399 m a su-sudoeste, em Romariz. No que se refere à precipitação média anual, esta aumenta à medida que nos afastamos do vale do rio Douro, para sul, desde os $1000 \mathrm{~mm}$ até aos $1800 \mathrm{~mm}$ nas áreas mais elevadas da bacia (Daveau, 1977).

O setor em estudo insere-se num contexto de planície aluvial relativamente larga e aplanada (largura máxima de aproximadamente $850 \mathrm{~m}$ ), recebendo o escoamento de $36,8 \mathrm{~km}^{2}$ da área total da bacia do rio Uíma (Figura 1C). O segmento do rio considerado para a modelação tem início a cerca de $11 \mathrm{~km}$ da sua cabeceira e abrange um comprimento de aproximadamente 5,1 $\mathrm{km}$ (Figura 1D). No setor modelado, a altitude mínima é de $113 \mathrm{~m}$ e a máxima de $280 \mathrm{~m}$ e o declive médio é de 5,9\%. O uso do solo ao longo da planície é pouco diversificado, sendo ocupado sobretudo por espaços florestais e áreas agrícolas, com a presença de alguns aglomerados populacionais dispersos.

\section{Metodologia}

O ensaio metodológico contemplou quatro etapas (Figura 2): a) a preparação dos dados de base necessários à modelação, i.e., altimétricos, de precipitação e estimação de caudais; b) a simulação hidráulica no software Hec-Ras; c) a produção dos resultados no software ArcGis; d) o cálculo da perigosidade, construindo-se, para o efeito, uma matriz de intensidade-probabilidade (Merz et al., 2007; Moel et al., 2009). 

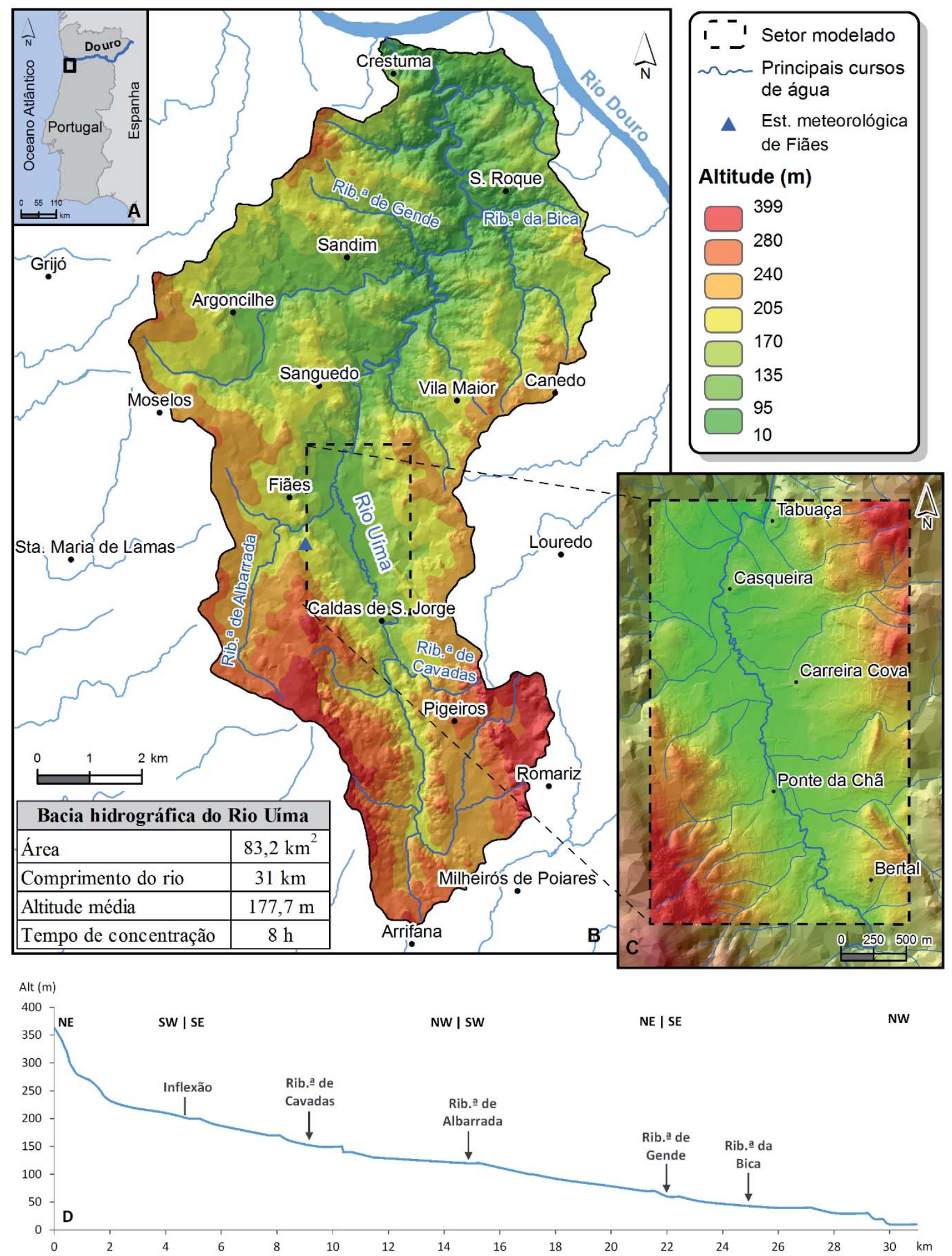

Figura 1 - Enquadramento da área de estudo e do setor analisado: (A) localização da bacia hidrográfica do rio Uíma em Portugal, (B) hipsometria da bacia hidrográfica do rio Uíma e localização do setor modelado, (C) hipsometria do setor modelado, (D) perfil longitudinal do rio Uíma. 


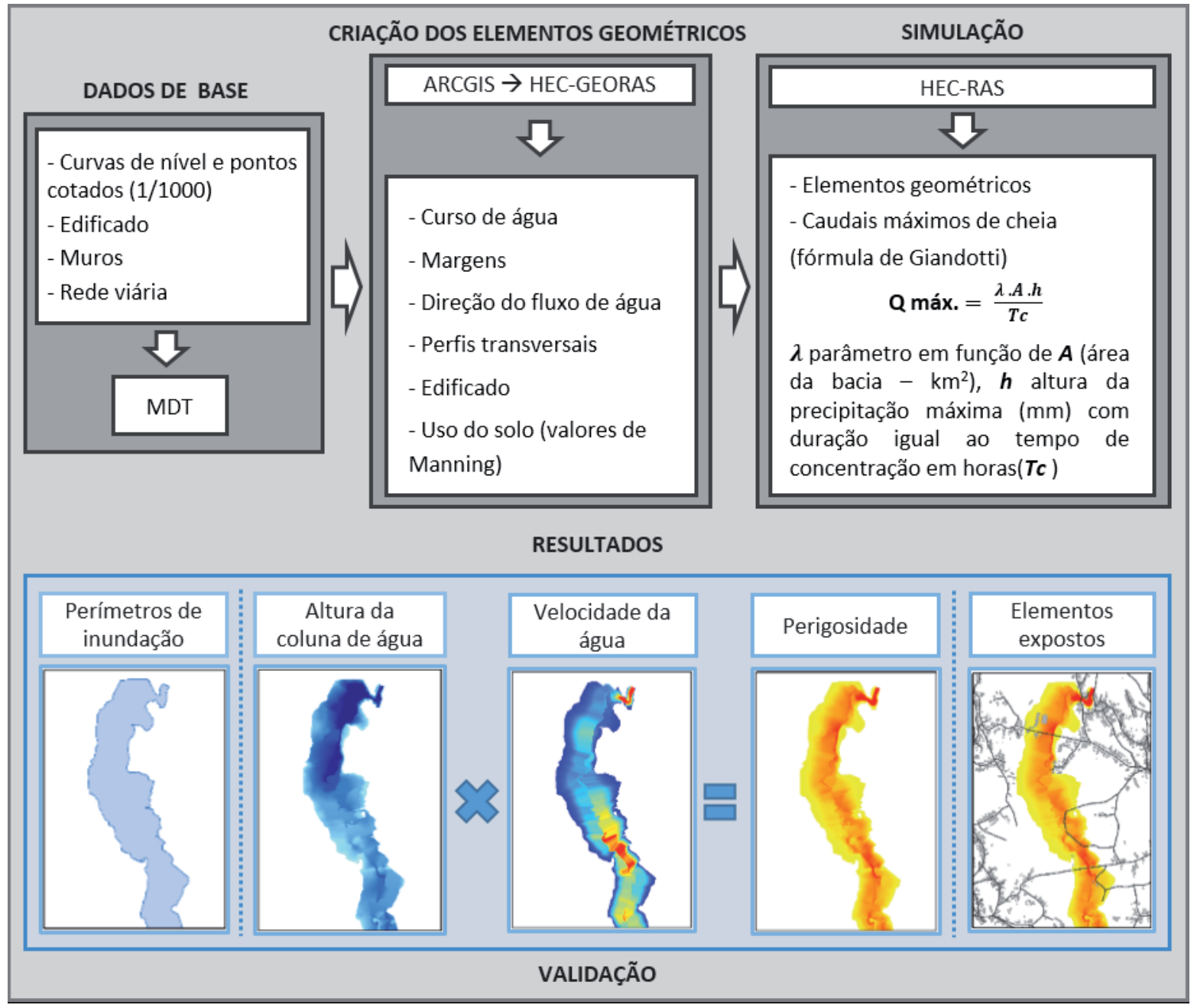

Figura 2 - Esquema metodológico seguido para a obtenção dos perímetros de inundação, altura da coluna de água, velocidade da água, perigosidade e identificação dos elementos expostos.

Para uma modelação hidráulica mais realista e rigorosa dos perímetros de inundação, deve ser utilizada cartografia de base pormenorizada, à escala $1 / 10000$ no máximo. Segundo Santos (2011) e Warner et al. (2009), para se obterem resultados fiáveis, a modelação requer um modelo digital de terreno detalhado, gerado com curvas de nível equidistantes até $5 \mathrm{~m}$. No setor em estudo, o MDT foi produzido com curvas de nível equidistantes de $1 \mathrm{~m}$, e a partir deste, criaram-se os elementos geométricos (dados de entrada do Hec-Ras), através da extensão Hec-GeoRas do ArcGis. Estes elementos dizem respeito ao centro geométrico do curso de água, às margens, à direção do fluxo de água, aos perfis transversais, às obstruções à circulação da água, como o edificado, e o uso do solo $\left(\operatorname{COS} 2007^{3}\right)$ com os respetivos valores de Manning (Van Der Sande, 2003). Para além da geometria, a simulação no Hec-Ras requer também os valores dos caudais máximos de cheia. No setor modelado, estes valores foram prédeterminados para os períodos de retorno de 10, $50 \mathrm{e}$ 100 anos, com base na fórmula de Giandotti. Para o efeito utilizaram-se os valores de precipitação mensal da estação meteorológica de Fiães (SNIRH), próxima do setor modelado (Figura 1B), e considerou-se um tempo de concentração da área contributiva para o setor modelado de $6 \mathrm{~h}$ (Tabela 1), também calculado com base na fórmula de Giandotti. Da aplicação da fórmula de Giandotti resultou um caudal máximo em 10 anos de $172,3 \mathrm{~m}^{3} / \mathrm{s}$, em 50 anos de $253 \mathrm{~m}^{3} / \mathrm{s}$ e numa cheia centenária de $286,2 \mathrm{~m}^{3} / \mathrm{s}$ (Tabela 1 ).

\footnotetext{
${ }^{3}$ http://www.igeo.pt/e-IGEO/egeo_downloads.htm
} 
Tabela 1: Características da área da bacia hidrográfica do rio Uíma que contribui com escoamento para o setor em estudo e valores dos caudais máximos de cheia obtidos pela fórmula de Giandotti para os períodos de retorno de 10 , 50 e 100 anos.

\begin{tabular}{|c|c|c|c|c|}
\hline & Características da área & & Caudais $\mathrm{m}$ & ximos de \\
\hline & Área & $36,8 \mathrm{~km}^{2}$ & - Fórmula d & Giandotti - \\
\hline & Comprimento do rio & $15,9 \mathrm{~km}$ & T 10 anos & $172,3 \mathrm{~m}^{3} / \mathrm{s}$ \\
\hline & Altura média & $102 \mathrm{~m}$ & T 50 anos & $253 \mathrm{~m}^{3} / \mathrm{s}$ \\
\hline $0^{1} y^{2} \mathrm{~km}$ & Tempo de concentração & $6 \mathrm{~h}$ & T 100 anos & $286,2 \mathrm{~m}^{3} / \mathrm{s}$ \\
\hline
\end{tabular}

Após o processamento e a simulação dos dados no Hec-Ras, foram exportados para o ArcGis, onde se obtiveram os resultados finais para os diferentes períodos de retorno considerados, designadamente os perímetros de inundação, a altura da coluna de água e a sua velocidade. A determinação da perigosidade a cheias baseou-se numa matriz de intensidade-probabilidade que relaciona a altura da coluna de água e a sua velocidade (intensidade) com a recorrência dos eventos, como é proposto nos trabalhos de Merz et al. (2007) e Moel et al. (2009). Com efeito, estes parâmetros foram normalizados para uma escala de 0 a 1 (Drobne e Lisec, 2009) através da equação (1):

$$
x_{i}=\frac{\left(R_{i}-R_{\min }\right)}{\left(R_{\max }-R_{\min }\right)} \cdot S R
$$

em que, $\boldsymbol{R}_{i}$ corresponde ao raster de cada parâmetro para cada período de retorno considerado, $\boldsymbol{R}_{\min }$ ao valor mínimo do raster, $\boldsymbol{R}_{\max }$ ao valor máximo do raster e $\boldsymbol{S} \boldsymbol{R}$ ao valor de variação da escala (standartizada).

Posteriormente à normalização, através da equação (2), procedeu-se à ponderação dos rasters com base na matriz, atribuindo-se uma ponderação maior aos parâmetros com período de retorno menor, que apresentassem elevados valores de intensidade $(0,5)$ e uma menor ponderação ao período de retorno de 100 anos e cuja intensidade é mais baixa $(0,2)$. Apesar da cheia centenária ser potencialmente mais perigosa devido às alturas da coluna de água e à velocidade que podem atingir, a sua probabilidade de ocorrência é menor, tal como traduzido na matriz de intensidade-probabilidade e como proposto nos trabalhos mencionados. Para esta equação, $\boldsymbol{P}_{i}$ corresponde ao parâmetro ponderado, $\boldsymbol{w}_{i t}$ à ponderação atribuída a cada parâmetro $i$ para cada período de retorno considerado $t$.

$$
\mathrm{P}_{i}=\Sigma W_{i t}
$$

O mapa de perigosidade a cheias resultou da multiplicação dos rasters ponderados, segundo o período de retorno, dos parâmetros da altura da coluna de água e da velocidade da mesma. Neste mapa final foram incluídos os elementos expostos identificados no campo e assinalados na cartografia planimétrica municipal, por classe de perigosidade (de muito baixa a muito elevada), à sua ocorrência, nomeadamente o edificado e os lanços de estradas. Os resultados foram validados com base no trabalho de campo desenvolvido por um dos autores, nomeadamente através do registo das marcas de cheia, inquéritos aos habitantes da área e fotografias da cheia de 2001.

\section{Resultados}

A figura 3 apresenta os resultados da modelação hidráulica efetuada. Assim, os perímetros de inundação para os períodos de retorno de 10, 50 e 100 anos, representados na figura $3 \mathrm{~A}$, não apresentam grandes diferenças em termos de extensão, até sensivelmente, metade do setor modelado. As maiores variações no espraiamento da água verificam-se sensivelmente a partir da localidade de Carreira Cova, sobretudo na margem esquerda do rio Uíma, onde a planície é larga e menos inclinada (Figura 4B, perfis 2 e 3). No total, a área correspondente ao perímetro de inundação para um período 
de retorno de 100 anos é de $896936 \mathrm{~m}^{2}$ e para 10 anos, de $791015 \mathrm{~m}^{2}$. Na figura 3B está representada a altura da coluna de água para uma cheia centenária. Como se pode observar, a água atinge maior altura a montante das pontes ou pequenos açudes, nomeadamente em Tabuaça e Casqueira e no setor a montante, onde o vale é mais estreito (Figura 4B, perfil 1). Esses elementos funcionam como obstáculos à livre circulação da água ao longo do seu percurso, promovendo uma subida do nível da água a montante. Os perfis transversais traçados evidenciam as características do vale ao longo do setor modelado, que como se referiu é mais estreito a montante e, por isso, condiciona o espraiamento da água pela planície (cerca de $89 \mathrm{~m}$ de extensão). Por outro lado, a meio do setor, o fundo do vale é mais amplo e aplanado, o que se reflete na extensão da cheia por aproximadamente 450 $\mathrm{m}$ da planície aluvial (Figura 4B, perfil 2). No último perfil (Figura 4B, perfil 3), traçado a montante da ponte de Tabuaça, verifica-se que a altura da água aumenta para aproximadamente $3 \mathrm{~m}$, dado o constrangimento que a ponte exerce à passagem da água para jusante.
Em termos quantitativos, para um período de retorno de 100 anos, a altura máxima que a água pode alcançar é de 5,5 m, enquanto para uma cheia recorrente (T10 anos) esse valor diminui para 4,58 $\mathrm{m}$. Quanto à velocidade da água no setor modelado são visíveis os segmentos do rio onde esta é mais elevada. Realça-se novamente o local de Tabuaça e o setor montante até à Ponte da Chã, e também o segmento do rio a jusante da localidade de Carreira Cova. Nestes locais, a velocidade máxima da água é de $6 \mathrm{~m} / \mathrm{s}$ para um período de retorno de 100 anos (Figura 3C).

A figura 5 representa o mapa da perigosidade à ocorrência de cheias, resultante da aplicação de uma matriz de intensidade-probabilidade. A relação efetuada nesta matriz significa que quanto maior a intensidade, ou seja, os valores da altura da coluna de água e da velocidade da água e quanto mais recorrente for a cheia, maior será a perigosidade do local à ocorrência de cheias. Pelo contrário, a perigosidade é mais baixa em áreas afetadas excecionalmente (T100anos) e cuja intensidade é baixa. Desta forma, no setor modelado

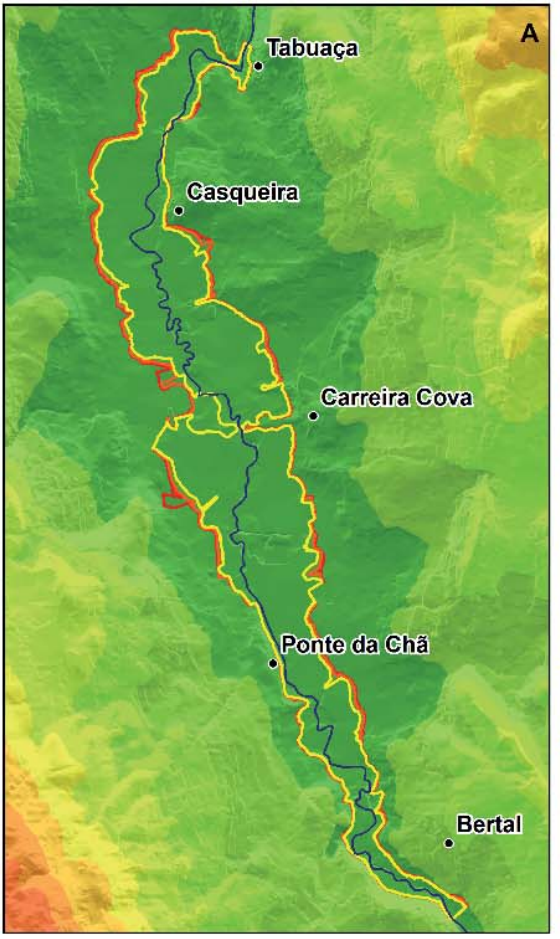

Perimetros de inundação (periodos de retorno) $\square 10$ anos $\square 50$ anos $\square 100$ anos Altitude ( $m$ ) $\begin{array}{llllllllll}113 & 140 & 160 & 180 & 200 & 220 & 240 & 260 & 280 & 289\end{array}$

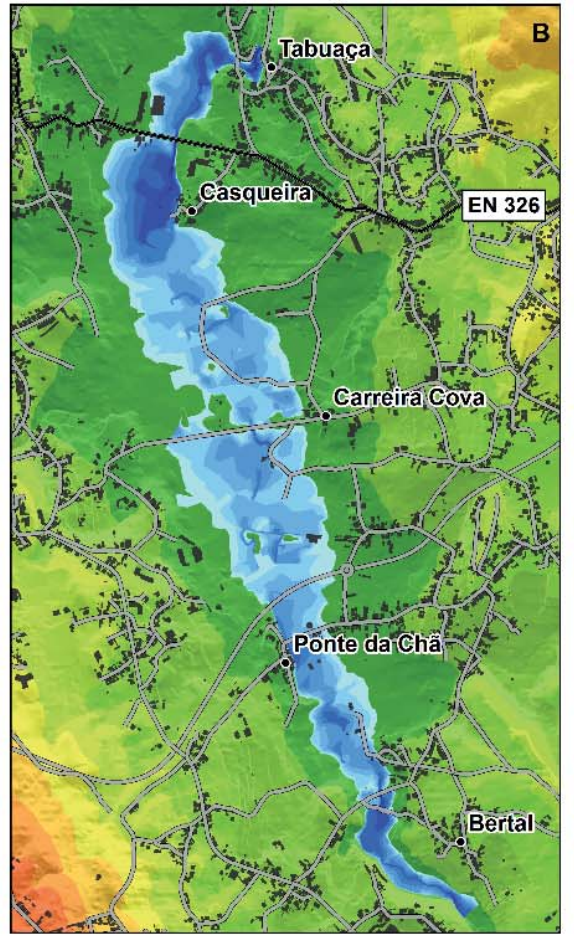

Altura da coluna de água $(\mathrm{m})$ - T100 anos

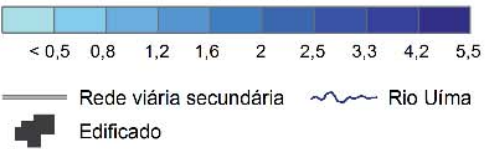

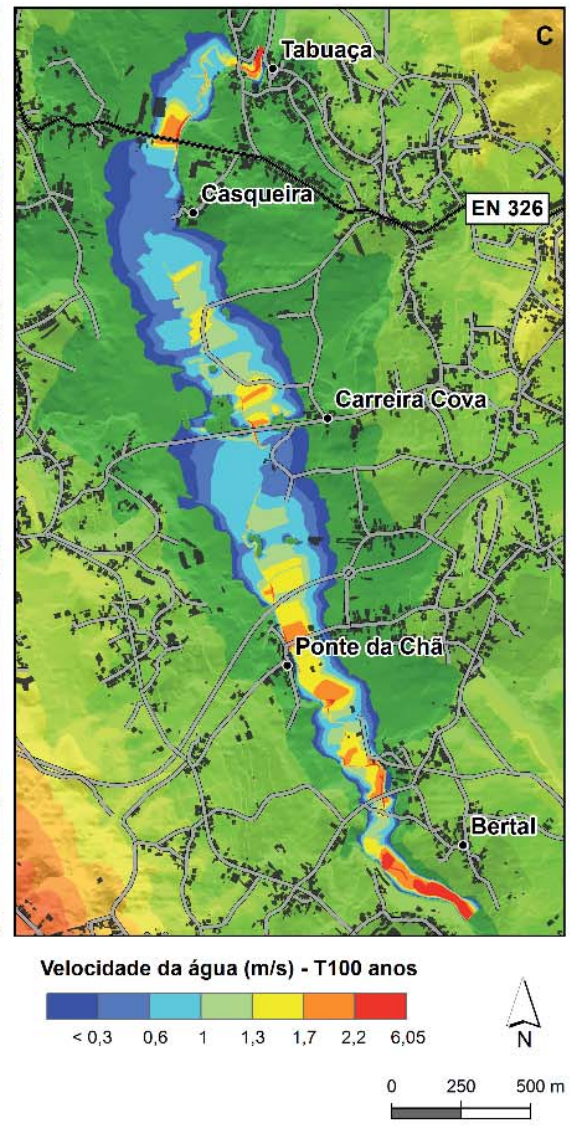

Figura 3 - Resultados da modelação hidráulica: (A) Perímetros de inundação para os períodos de retorno de 10, 50 e 100 anos, (B) Altura da coluna de água para o período de retorno de 100 anos, (C) Velocidade da água para o período de retorno de 100 anos. 
Marafuz I. et al.
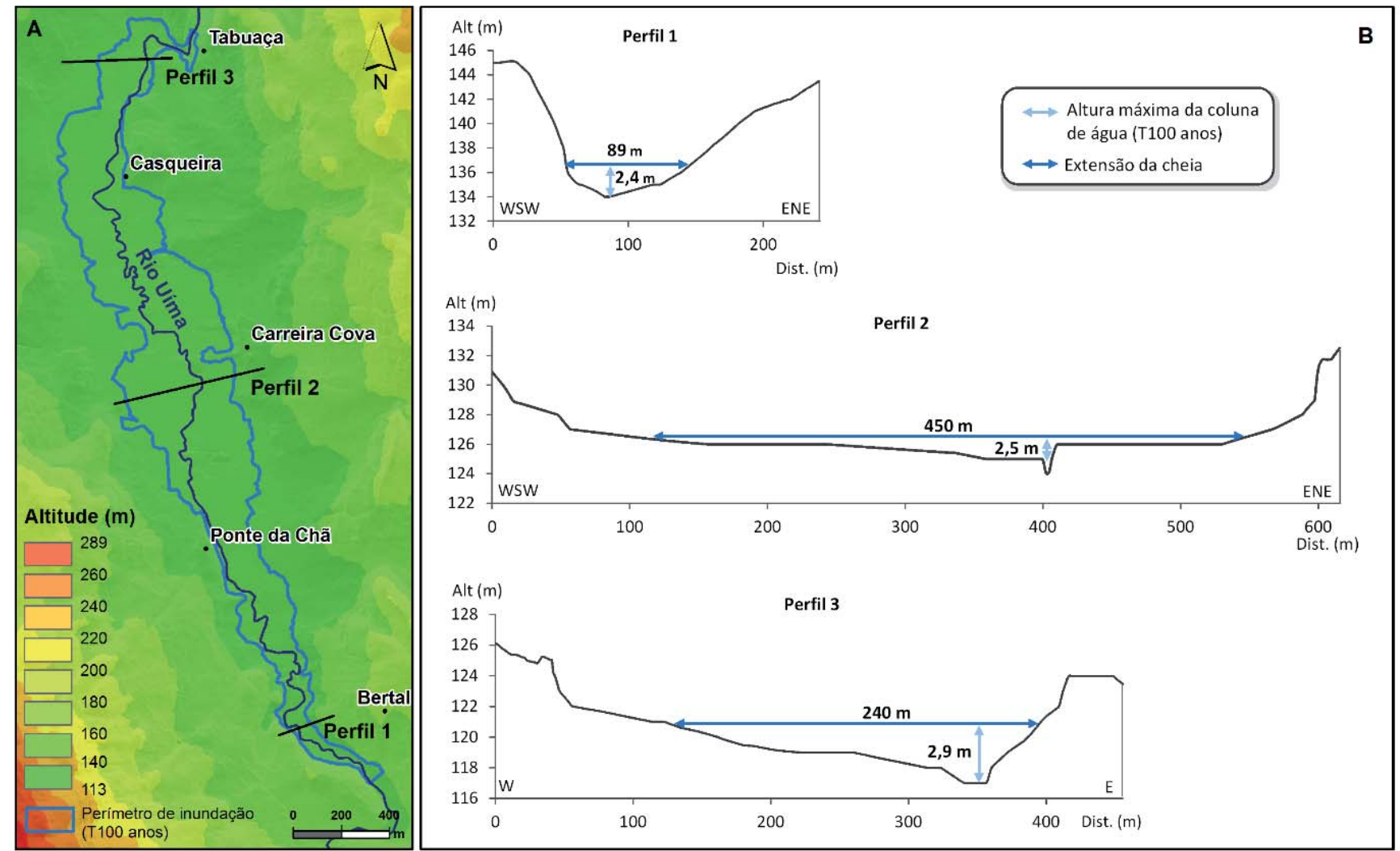

\section{PONTE DE CHÃ}
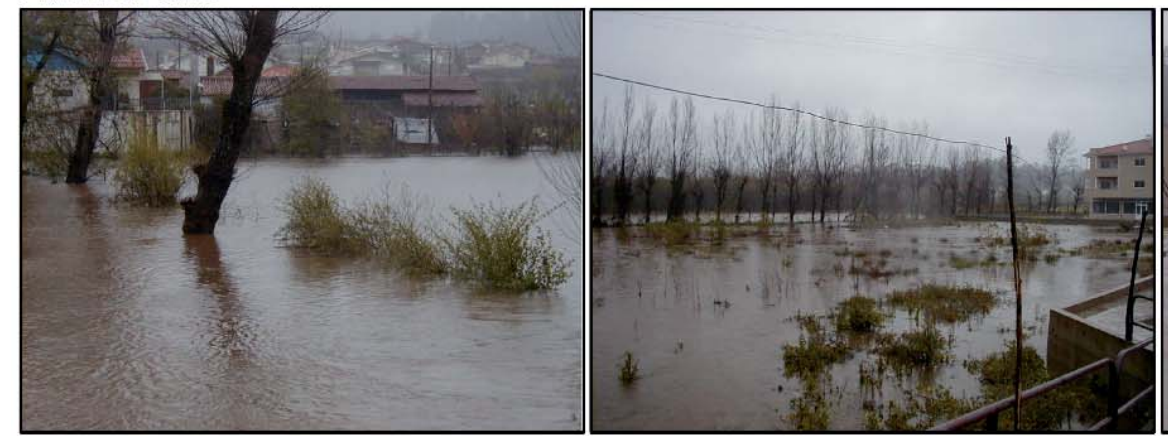

c
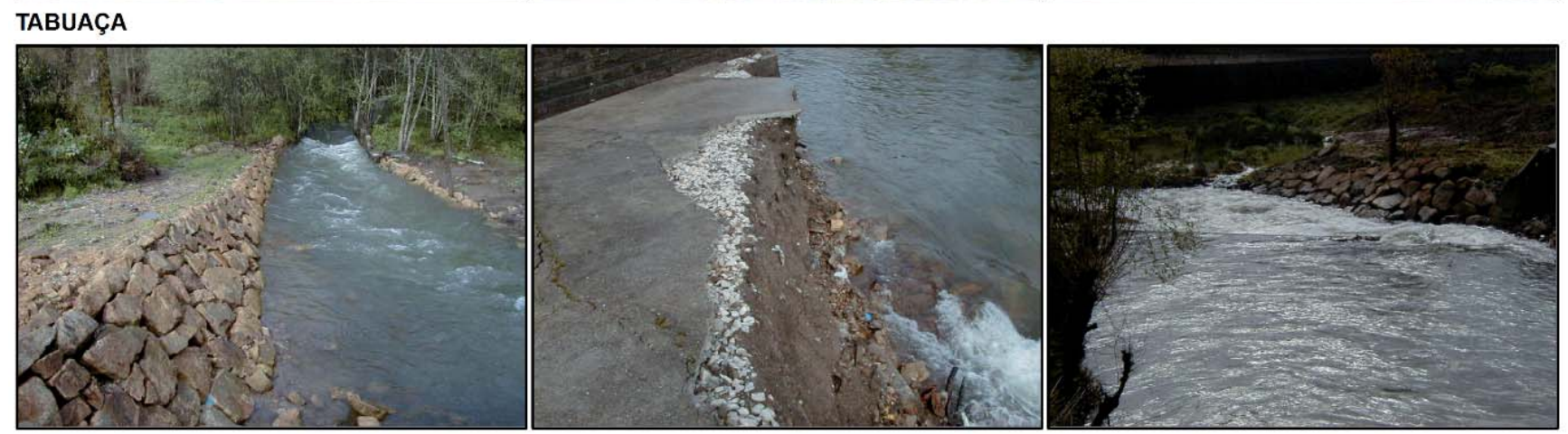

Figura 4 - Perfis transversais e fotografias da cheia de 2001: (A) localização dos perfis transversais traçados ao longo do setor modelado; (B) perfis transversais com a indicação da altura máxima da coluna de água e extensão da cheia para um período de retorno de 100 anos; (C) imagens relativas às cheias de 2001 para as localidades de Ponte da Chã e Tabuaça. 
existem três locais que, pela combinação dos fatores anteriormente mencionados apresentam uma perigosidade muito elevada: as margens do leito do rio junto da localidade de Tabuaça, o setor em que a Estrada Nacional 326 atravessa a planície aluvial e o local mais a montante, próximo de Bertal. Quanto aos elementos expostos existe um lanço de uma estrada secundária e um lanço da EN326 que se encontram em áreas de perigosidade muito elevada. Como se pode observar pela tabela da figura 5B, no total existem 56 habitações em áreas afetadas por cheias, sendo que a maioria se encontra em locais de perigosidade baixa e muito baixa. No que se refere à rede viária secundária, contabilizam-se 55 lanços afetados, num total de 10 estradas, embora a maioria também se encontre em áreas de baixa e muito baixa perigosidade. Alguns dos elementos afetados na cheia de 2001 podem ser observados nas fotografias da figura 5C, D, E, referentes às localidades de Tabuaça e Ponte da Chã.
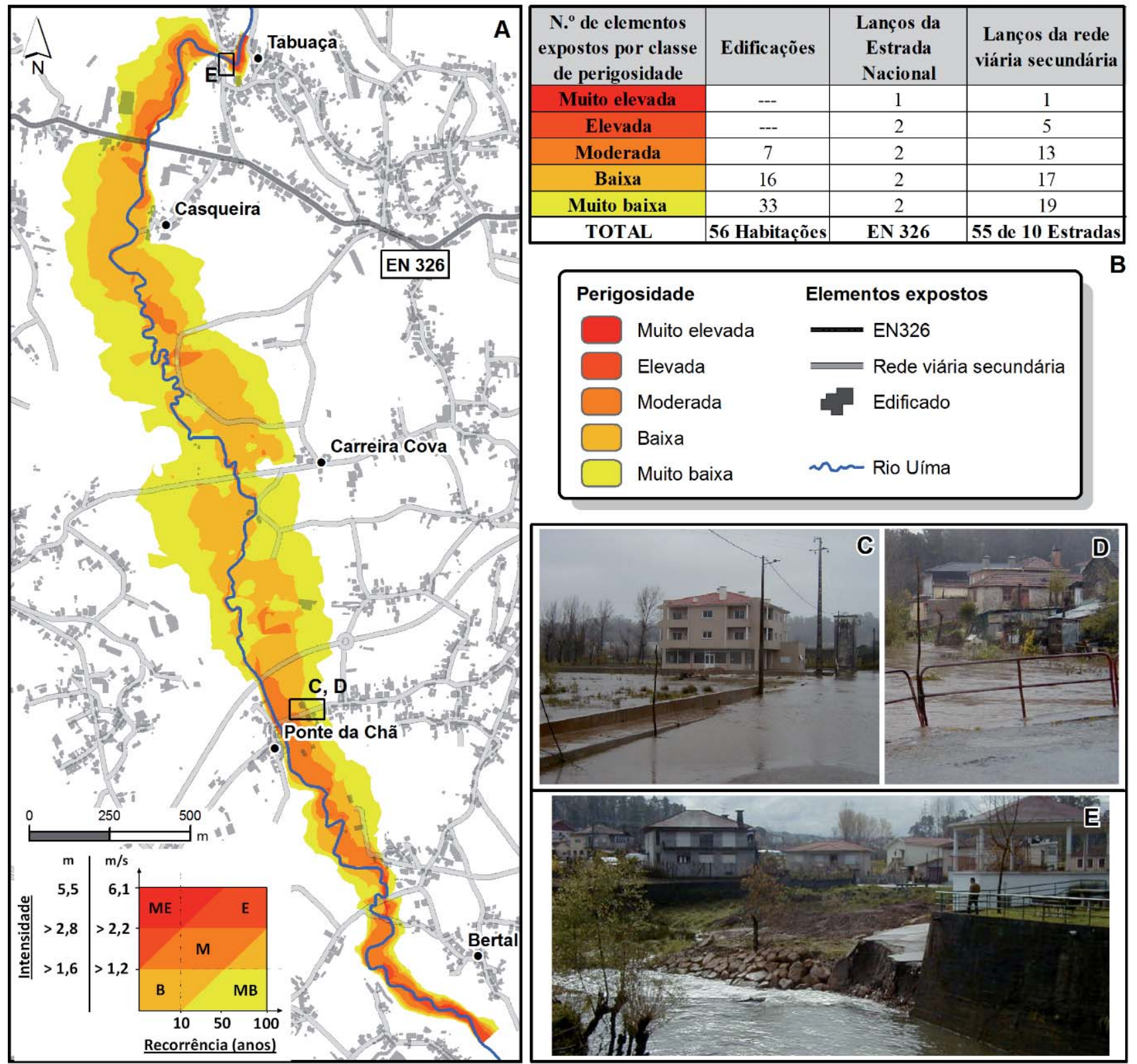

Figura 5 - Perigosidade à ocorrência de cheias: (A) mapa da perigosidade a cheias no setor em estudo e da localização dos elementos expostos; (B) quantificação dos elementos expostos por classe de perigosidade; (C) fotografia de uma habitação afetada pela cheia de 2001, em Ponte da Chã; (D) fotografia de uma estrada afetada pela cheia de 2001, em Ponte da Chã; (E) Fotografia da destruição de um muro de suporte de um largo em Tabuaça devido à cheia de 2001. 
Os resultados obtidos através deste exercício metodológico podem ainda ser melhorados com algum trabalho de campo, nomeadamente através da atualização e enriquecimento dos dados que serviram de base à geração do MDT. Por outro lado, verificou-se que na modelação dos perímetros de inundação devem ser incluídos os dados geométricos e os valores dos caudais dos afluentes do rio Uíma, para se obterem resultados mais ajustados aos perímetros de inundação observados durante o evento de 2001, especificamente nas áreas de confluência.

\section{Discussão e conclusões}

Na Europa, ainda é rara a elaboração de cartografia de perigosidade a cheias (Moel et al., 2009) para efeitos de avaliação e gestão dos riscos de inundação, e, neste contexto, a abordagem metodológica descrita demonstra que é possível cumprir, de forma rigorosa e realista, alguns dos requisitos da Diretiva 2007/60/CE. No entanto, destacam-se alguns aspetos a ter em consideração para a melhoria dos resultados: inserir na modelação o desenho das pontes existentes (Gonçalves, 2012), uma vez que funcionam como barreiras à passagem da água, e devem ser considerados os afluentes do rio Uíma que convergem para o segmento modelado. Por outro lado, também se salienta a escassez de estações meteorológicas com influência na área que contribui com escoamento para o setor modelado. Desta forma, apenas se utilizaram os dados de precipitação de uma estação (Fiães) no cálculo dos caudais máximos de cheia.

Ressalva-se ainda a importância da cartografia de base para uma delimitação rigorosa dos perímetros de inundação e da altura da coluna de água. Quanto mais pormenorizados forem os dados, mais rigorosos e aproximados da realidade serão os resultados da modelação. Na situação atual, para alguns municípios portugueses torna-se difícil elaborar estudos a uma escala de pormenor, visto que para grandes áreas nem sempre existe cartografia em escala adequada. Apesar disso, a cartografia pode ser atualizada com a inserção de novos elementos do terreno que não estejam incluídos e que possam influenciar os resultados finais (Gonçalves, 2012). Por outro lado, e à semelhança do que acontece um pouco por todo o país, as cheias no setor em estudo poderão ser agravadas pelo mau funcionamento ou subdimensionamento dos sistemas de drenagem de águas pluviais que convergem para as áreas de menor altitude.
A par desta problemática, refere-se a tendência para os solos saturarem e para a subida do nível freático após longos períodos de precipitação, contribuindo também para a intensificação destes eventos.

Os resultados apresentados são importantes para o ordenamento do território, já que contribuem para a melhoria do conhecimento das áreas problemáticas em termos de perigosidade e de elementos expostos. Desta forma, é possível estabelecer e propor restrições adequadas à construção ao longo da planície aluvial, considerando o grau de perigosidade associado a determinada área. Como exemplo, refere-se a necessidade de proibir/evitar a construção em áreas cujo perigo é elevado ou muito elevado e a possibilidade de se fazerem construções, desde que se tomem medidas apropriadas de proteção contra as cheias, no caso das áreas com perigosidade moderada/baixa (Alphen et al., 2009, Griffiths, 2010). A cartografia resultante deste ensaio metodológico inclui informação necessária para o estabelecimento de medidas de mitigação e de prevenção, bem como de extrema importância para o bom desempenho da proteção civil.

\section{Agradecimentos}

Os nossos agradecimentos à Câmara Municipal de Santa Maria da Feira pela cedência de cartografia de base relativa ao setor em estudo, à escala 1/1000. Este trabalho foi realizado no âmbito da revisão do Plano Municipal de Emergência e Proteção Civil do município, uma parceria entre a Faculdade de Letras da Universidade do Porto, a empresa Municípia SA e a Câmara Municipal de Santa Maria da Feira.

\section{Referências bibliográficas}

ALPHEN, J. VAN; MARTINI, F.; LOAT, R.; SLOMP, R.; PASSCHIER, R. Flood risk mapping in Europe, experiences and best practices. Journal of Flood Risk Management, v. 2, issue 4, p. 285-292, 2009.

BARREDO, J.I. Major flood disasters in Europe: 1950-2005. Natural Hazards, 42, p. 125-148, 2007.

BATEIRA, C.; SANTOS, M.; HERMENEGILDO, C.; SOARES, L.; PEREIRA, S.; QUARESMA, I.; SANTOS, P. Distribuição temporal dos desastres naturais de origen hidro-geomorfológica em Portugal Continental (1865-2010). Atas do VI Congresso Nacional de Geomorfologia, Coimbra, p. 110-114, 2013.

DAVEAU, S. Répartation et Rythme des Précipitations au 
Portugal. Memória do Centro de Estudos Geográficos, n³, Lisboa, 1977. 192 p.

Decreto-Lei n. ${ }^{\circ}$ 166/2008. Ministério do Ambiente, do Ordenamento do Território e do Desenvolvimento Regional de Portugal - DR. 1. ${ }^{a}$ Série. N. ${ }^{\circ} 162$, p. 5865-5884, 22 de Agosto de 2008.

Decreto-Lei n. ${ }^{\circ}$ 115/2010. Ministério do Ambiente e Ordenamento do Território de Portugal - DR. I Série. N. ${ }^{2} 206$, p. 4757-4764, 22 de Outubro de 2010.

Diretiva 2007/60/CE do Parlamento Europeu e do Conselho de 23 de Outubro de 2007, relativa à avaliação e gestão dos riscos de inundações. Jornal Oficial da União Europeia, L. 288, p. 27-34, 2007.

DOUBEN, K.-J. Characteristics of river floods and flooding: A global overview, 1985-2003. Irrigation and Drainage, 55, p. 9-21, 2006.

DROBNE, S.; LISEC, A. Multi-attribute decision analysis in GIS: weighted linear combination and ordered weighted averaging. Informatica, 33, p. 459-474, 2009.

DU, J.; QIAN, L.; RUI, H.; ZUO, T.; ZHEN, D.; XU, Y., XU, $\mathrm{C}$-Y. Assessing the effects of urbanization on annual runoff and flood events using an integrated hydrological modeling system for Qinhuai river basin, China. Journal of Hydrology, v. 464465, p. 127-139, 2012.

EM-DAT Database (The International Disaster Database). Centre for Research on the Epidemiology of Disasters - CRED. Disponível em: http://www.emdat.be/database

GOMES, A. Evolução Geomorfológica da Plataforma Litoral entre Espinho e Águeda. 2008. 339 p. Tese (Doutoramento em Geografia Física) - Faculdade de Letras, Universidade do Porto, 2008.

GONÇALVES, A. A Delimitação de Perímetros de Inundação no Rio Leça - modelação hidráulica para duas áreas do concelho de Matosinhos. 2012. 126 p. Dissertação (Mestrado em Sistemas de Informação Geográfica e Ordenamento do Território) - Faculdade de Letras, Universidade do Porto.

GRIFFITHS, J. S. Investigating the role of landscape evolution in determining ground conditions for engineering: examples from South-West England. Geoscience in South-West England, 12, p. 177-187, 2010.

HOLLIS, G. E. The effect of urbanization on floods of different recurrence interval. Water Resources Research, v. 11, issue 3, p. $431-435,1975$.
JONKMAN, S. N. Global perspectives on loss of human life caused by floods. Natural Hazards, v. 34, issue 2, p. 151-175, 2005.

JULIÃO, R. P.; NERY, F.; RIBEIRO, J. L.; BRANCO, M. C.; ZÊZERE, J. L. Guia metodológico para a produção de cartografia municipal de risco e para a criação de sistemas de informação geográfica (SIG) de base municipal. ANPC, Lisboa, 91 p., 2009.

MERZ, B.; THIEKEN, A. H.; GOCHT, M. Flood risk mapping at the local scale: concepts and challenges. Flood Risk Management in Europe, 25, p. 231-251, 2007.

MOEL, H. de; ALPHEN, J. VAN; AERTS, J. C. J. H. Floods maps in Europe - methods, availability and use. Natural Hazards Earth System Science, 9, p. 289-301, 2009.

PEREIRA, S.; ZÊZERE, J.L.; QUARESMA, I.; VERDE, J.; FONSECA, I.L.; REIS, E. GIS database on hydrogeomorphologic disasters in Portugal (DISASTER Project). Actas de la XII Reunión Nacional de Geomorfología, Publican Ediciones, Santander, p. 163-166, 2012.

SANTOS, P. P.; TAVARES, A.; ANDRADE, A. Comparing historical-hydrogeomorphological reconstitution and hydrological- hydraulic modelling in the definition of floodprone areas - a case study in Central Portugal. Natural Hazards Earth System Science, 11, p. 1669-1681, 2011.

SANTOS, P.P.; TAVARES, A. O.; ZÊZERE, J. L. Risk analysis for local management from hydro-geomorphologic disaster databases. Environmental Science \& Policy, in press, 2014.

SNIRH (Sistema Nacional de Informação de Recursos Hídricos). Disponível em: http://snirh.apambiente.pt/

WARNER, J. C.; BRUNNER, G. W.; WOLFE, B. C.; PIPER, S. S. HEC-RAS: River Analysis System Applications Guide. US Army Corps of Engineers - Hydrologic Engineering Center. Davis, CA: California, 2009.

VAN DER SANDE, C.J.; DE JONG, S.M.; DE ROO, A.P.J. A segmentation and classification approach of IKONOS-2 imagery for land cover mapping to assist flood risk and flood damage assessment. International Journal of Applied Earth Observation and Geoinformation, 4, 217-229, 2003.

ZÊZERE, J. L.; PEREIRA, S.; TAVARES, A. O.; BATEIRA, C.; TRIGO, R. M.; QUARESMA, I., SANTOS, P. P.; Santos, M.; Verde, J. DISASTER: a GIS database on hydro-geomorphologic disasters in Portugal. Natural Hazards, in press, 2014. 